\title{
An Ovary with a Well-marked Fibrous Excrescence.
}

\author{
By Malcoly Caypbelt, M.A., M.B., F.R.C.S. (Edin.), \\ Clinical Gyncecological Tutor, Royal Infirmary, Edinburgh.
}

Is gynæcological surgery no question is more difficult to decide than that as to the treatment of "the second ovary." After removal of the ovarian tumour for which laparotomy has been undertaken, the operator has to decide rapidly, and before finally closing the abdomen, whether or not he is to totally unsex the patient, a question, the importance of which, from the patient's point of view, it is impossible to exaggerate. To the surgeon a dilemma presents itself, for should he leave an ovary, which at a subsequent date requires removal, his reputation cannot fail to suffer, for he has, however innocently, been the indirect cause of exposing his patient to the not inconsiderable risk of a second abdominal section. On the other hand, if he removes a patient's second ovary, which on careful examination is found free from any pathological changes, he does his patient an irreparable injury which is none the less real though the patient remains in ignorance of it.

Called on to make such an important decision it is little wonder that one welcomes as an important factor the presence of any marked physical abnormality in the remaining ovary. Yet, even aided by the presence of gross abnormalities in the ovary we may easily fall into error as the following case illustrates.

The clinical history presents no features of special interest. The patient was 34 years of age, she had had five children, the youngest æt. $2 \frac{1}{2}$ years. The right ovary was converted into a small cyst for the removal of which laparatomy was undertaken. After removal of the tumour, which was done without tapping the cyst, the left ovary was found on examination to be of normal size, but to have on its margin a well-marked cauliflower excrescence, further, over its surface were found numerous small cystic areas; having regard to the condition of the right ovary and the possibility that the outgrowth on the surface of the left ovary might be the result of papillomatous changes in its substance, it was decided to remove the left ovary. After removal the measurements were found to be:-Length, 3 c.m.; breadth, $1.7 \mathrm{c.m}$.; thickness, $1.5 \mathrm{c}$.m. The greatest diameters of the excrescence were 1 by $0.7 \mathrm{c.m}$. The excrescence, which was found to be firmly attached to the surface of the ovary by a comparatively thin base, 
presented an irregular surface, having a typically cauliflower appearance. (Fig. I.). A longitudinal section of the ovary was made, passing through the stalk of the excrescence. Naked-eje examination showed that the tissue forming the excrescence penetrated for some distance into the substance of the ovary; throughout the ovary there were found numerous small areas of degenerated tissue, most probably the remains of follicles which had undergone retrograde changes. On microscopic examination the excrescence was found to consist mainly of vascularised fibrous tissue; in the centre there was a small area in which the fibrous tissue had undergone necrotic changes (Figs. II. and III.); the coats of the vessels showed very marked thickening. The growth was entirely free from any elements suggesting malignancy.

As to the origin of the growth, while no definite explanation can be put forward, one would appear to be justified in regarding it ae most probably originating in connection with the function of ovulation. If this be so there are only two possibilities : either it arose in connection with a Graäfian follicle or a corpus luteum. In the former case the intact Graäfian follicle must have been extruded upon the ovarian surface and become the seat in the first instance probably of hæmorrhages and subsequently of connective tissue invasion. On this theory the extra-ovarian and intra-ovarian parts of the growth would be connected through the neck of the extruded follicle.

The other possibility is that the growth resulted from the rupture of a Graäfian follicle on the surface of the ovary, followed by an incomplete hernia of the corts of the follicle through the seat of rupture. On this theory the neck of the growth would represent the continuity between the extruded portion of the coats of the follicle and that part of the coats which remained intra-ovarian.

While various objections may be offered to both theories the latter seems at least to be more probable, as it affords a satisfactory explanation of many of the features of the growth.

1. The cauliflower appearance, on this theory, is easily explained as resulting from the natural infoldings of the coats, from which arise the strands of connective tissue which invade the primary bloodclot in a normally situated corpus luteum.

2. The rascularisation of the growth would be produced by the ingrowth of new vessels, along with the connective tissue from the theca interna and the theca externa, as in the corpus luteum.

3. If the growth has an origin from a ruptured follicle, the possibility of its having been developed from a corpus luteum of pregnancy would not only offer an explanation of its size, but further, 


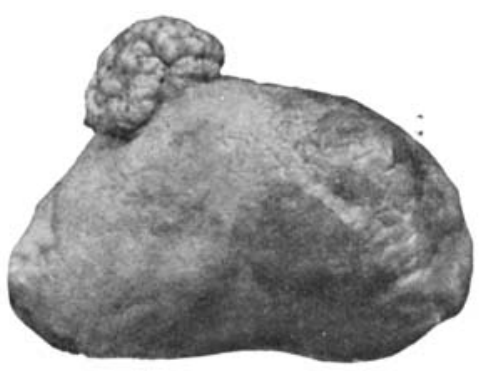

Figr. I.

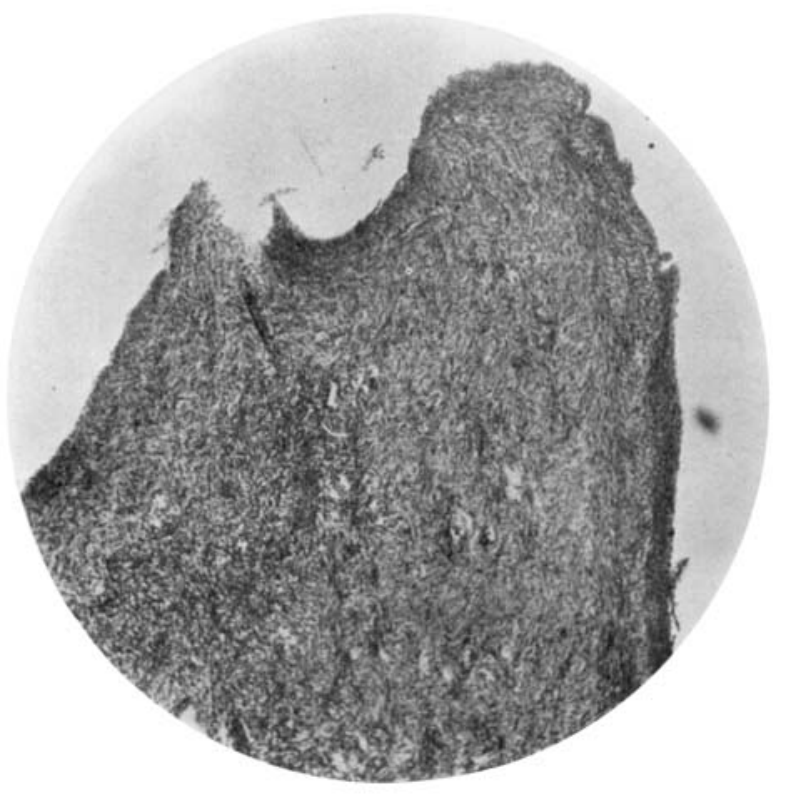

II. Microphotograph (low power) showing the connective tissue forming the greater part of the excrescence. 


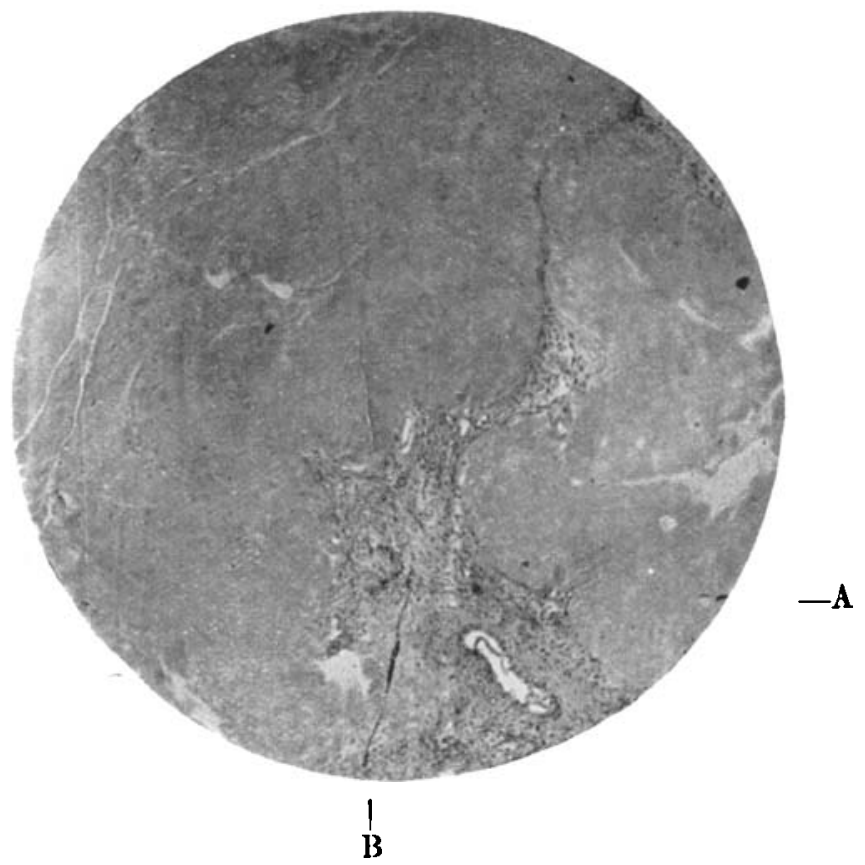

III. Microphotograph (higher power than II.) shows one of the necrotic areas.

A.-Typical part of section showing structureless necrotic tissue.

B.-Ares in which the outlines of the comnective tissue cells are still distinct. 
the complete state of the connective tissue development would coincide with the remoteness of the last pregnancy.

As to the possible further development of the growth, had the ovary not been removed, little need be said. In none of the sections examined microscopically is there any appearance of active tissue change. Moreover, the vessel walls throughout show a marked thickening, and it seems probable that, despite the periodic menstrual hyperæmia of the ovary, they would have become progressively less able to convey blood to the growth which probably would, on account of insufficient nutrition, have undergone retrogressive changes. 